\title{
laborhifórico
}

ISSN 2359-6910

https://revistas.ufrj.br/index.php/lh/

ARTIGO

Recebido em 18 de fevereiro de 2020

Aprovado em 9 de maio de 2020

\section{Americanus pinxit: os artistas da Real expedição botânica do Novo Reino de Granada (1783-1816) desde a epistemologia visual}

Americanus Pinxit: the Artists of the Royal Botanical Expedition of the New Kingdom of Granada (1783-1816) from the Visual Epistemology View

DOI: https://doi.org/10.24206/1h.v6i2.32394

Juan Ricardo Rey-Márquez

Investigador del Centro de Investigaciones en Arte Materialidad y Cultura (Centro Materia), docente de la Maestría en curaduría de las artes visuales, de la Universidad Nacional de Tres de Febrero, Argentina. Profesor de historia del arte colonial, Carrera de gestión e historia de las artes, Universidad del Salvador, Argentina.

E-mail: jrmarquez@untref.edu.ar ORCID: http://orcid.org/0000-0003-1556-6368 


\section{RESUMO}

Os desenhos feitos para a Real expedição botânica do Novo Reino de Granada (1783-1816) são vistos como exemplos de um gênero de representação particular dedicado ao estudo do reino vegetal. Mas o seu conteúdo vai além do trabalho específico numa empresa científica. Nesses desenhos é apontada a importância do olhar botânico, pela evidente colaboração em equipe do cientista e do artista, o que lembra a ideia da arte como ancilla ecclesiae, mas neste caso a serviço da ciência. A densidade da obra Oficina de pintores apresenta um caso em que os desenhos parecem ter o objetivo de substituir os espécimes vivos. É apropriado restringir a visão deste grupo excepcional à ilustração científica? Ao reduzir a sua produção a simples ilustrações, não se está negando a contribuição da arte à ciência ao pensá-la como ancilla scientiae? Se pensarmos no conforto das classificações historiográficas, a resposta é sim. Mas se pensarmos em um sentido amplo a resposta é negativa. $\mathrm{O}$ trabalho das imagens como fontes junto às representações escritas propõem uma utilização do visual que mistura a arte e a ciência, pois esses desenhos botânicos apresentam um problema de conhecimento através da imagem, porém um exemplo de epistemologia visual.

Palavras-chave: Expedição botânica do Novo Reino de Granada. Epistemologia visual. Historiografia da arte.

\section{ABSTRACT}

The drawings from the Royal Botanical Expedition to Nueva Granada (1783-1816) are taken as an example of the genre of the depiction of nature. Nevertheless, their content goes beyond the specific task of a scientific endeavor. It is usually appointed the importance of botanic observation on those works for the evident collaboration between the scientist and the artist. That aspect reminds the idea of the art as ancilla ecclesiae but -in this case- as the servant of science. But the depth of the Painters Workshop work presents a situation in which the drawings seem to have the object to replace the living samples $i^{i t}$ is appropriate to narrow the gaze of this exceptional group to the idea of scientific illustration? With the reduction of their work to illustrations jare we not denying the art contribution to the science as it would be ancilla scientiae? If we think according to the rigid historiographical classifications, the answer if affirmative; if thinking on a broader sense, then is the opposite. The work with images as sources, together with the writing ones, suppose a notion of the visual that mixes art and science since those botanical drawings present a problem of knowledge trough images. Therefore, an example of visual epistemology

Keywords: Botanical Expedition to Nueva Granada. Visual epistemology. Art historiography. 


\section{Introdução: olhar do cientista, mão de $\operatorname{artista}^{1}$}

Os artistas da Real expedição botânica do Novo reino de Granada (1783-1816) são geralmente vistos como especialistas num tipo particular de representação dedicado ao estudo do reino vegetal. No entanto, sua versatilidade foi muito além do trabalho específico esperado em uma empresa botânica. Sob a direção do médico de Cádiz José Celestino Mutis (Cádiz, 1732- Santafé de Bogotá, 1808), no Novo Reino de Granada foi criada em 1783 uma expedição composta por dois botânicos, o diretor e Eloy Valenzuela (Girón, 1756 - Bucaramanga, 1834), e um artista, Pablo Antonio García del Campo (Santafé de Bogotá, 1744-1814), com a proteção e o patrocínio do rei Carlos III. Ao longo de quase três décadas esse grupo cresceu e especializou-se nas artes com a formação da Oficina de pintores e a Escola gratuita de pintores. Assim a equipe artística chegou a ter quarenta desenhistas, ${ }^{2}$ ainda que não tivessem trabalhado todos ao mesmo tempo. Enquanto pela parte botânica a equipe não aumentou, Mutis continuou sendo o botânico principal e após a aposentadoria de Valenzuela, ele não teve substituto. Por esta razão, o nosso principal objetivo é compreender a motivação desse crescimento tão desigual. A nossa hipótese é que para o diretor da expedição foi mais importante a representação visual, do que se poderia pensar. Por isso, Mutis teve mais artistas para fazer desenhos das plantas que botânicos para descrevê-las, porquanto os ícones superam em número o trabalho de taxonomia. De fato, o total de descrições botânicas encontradas até agora é 707. Essa diferença entre material visual e escrito pode ser interpretada de várias maneiras: pode-se pensar que o restante dos escritos está perdido, uma vez que após a morte de Mutis houve alegações de roubo contra o mordomo da expedição, Salvador Rizo Blanco. O manuscrito pode ter sido perdido durante a Guerra da Independência (1810-1819) ou quando os materiais da Expedição foram trazidos para a Espanha, em 1816. Os trabalhos de zoologia, ornitologia e as pinturas de Castas neogranadinas desapareceram na chegada à península ibérica. Ou simplesmente o manuscrito da flora de Bogotá, como se chama na historiografia o texto de Mutis, não foi escrito. Todas essas possibilidades foram tratadas pelo historiador colombiano da história da ciência José Antonio Amaya, para quem o manuscrito provavelmente não existe porque não foi escrito (2005, v. 1, p. 72-73). Mesmo se esse fosse o caso, o problema permanece.

${ }^{1}$ Este trabalho faz parte do projeto de pesquisa "Nulla dies sine linea: el dibujo y el grabado como herramientas de conocimiento. Epistemología visual en Iberoamérica en los siglos XVII al XIX” (Código 32/466 A). Centro de Investigación en Arte, Materia y Cultura MATERIA, IIAC-UNTREF.

${ }^{2}$ Segundo González Bueno (2009), são 41 os desenhistas que assinaram as suas obras com a Expedição, mas segundo González e Amaya o numero é de 63 (1996) entre os pintores oficiais da Oficina de pintores e os alunos da Escola gratuita de desenho e pintura. 
É provável que a Expedição, que teve pesquisas de zoologia, biologia, astronomia e mineralogia além de botânica, não tivesse os materiais necessários para completar a classificação taxonômica desejada. Tais materiais, as publicações botânicas atualizadas da época, chegaram tarde à América devido à situação da época: a guerra da Espanha com a Inglaterra no último quartel do século 18, as revoltas populares - chamadas de comuneros- contra aumentos de impostos para sustentar o sistema de defesa espanhol, depois as invasões napoleônicas no século 19 e os problemas internos do vice-reinado de Nova Granada foram um obstáculo à chegada de livros da Europa. Embora Alexander von Humboldt tenha dito que a biblioteca de Mutis era tão completa quanto a de Joseph Banks (HAMY, 1905, p. 126), ${ }^{3}$ o prussiano encontrou o diretor da expedição quando ele era muito velho, em 1801. Portanto, essa descrição, se não for um exagero, nos fala sobre o momento final da biblioteca botânica, mas não nos diz quando os livros chegaram. Isso, juntamente com a falta de botânicos taxonômicos ao trabalho, explica em grande parte o fraco progresso das descrições cientificas.

No entanto, os trabalhos da oficina de pintores avançavam bastante no desenvolvimento de técnicas e na produção de imagens. A equipe de desenho e pintura cresceu de 1783, quando havia apenas um pintor, para uma oficina especializada que produzia suas próprias cores. Além disso, eles trabalharam numa técnica nova que misturava têmpera, miniatura e tinta-da-china e faziam um tipo de obra inédita no vice-reinado. Mas o contraditório era que para fazer as pinturas, era necessária a orientação do botânico. Em outras palavras, o avanço artístico exigia maior precisão na observação científica. Sendo assim, é estranho que o mesmo esforço não tenha sido feito nas descrições taxonômicas. Ou, olhando o problema de maneira diferente, não é uma contradição: com tão poucos botânicos (Mutis e Valenzuela), o conselho permanente aos desenhistas foi uma tarefa que dificultou a taxonomia.

No entanto, a identificação desses artistas é muito importante. O problema é que a obra artística da expedição mutisiana não tem nem identificação dos autores, nem a data de realização dos desenhos. Em uma produção de mais de seis mil obras, é impressionante que existam poucos assinados por esses pintores ativos desde o último quartel do século XVIII, até o começo do século seguinte, ou seja, o período final do domínio hispânico e os primórdios da vida republicana. No entanto, apesar do anonimato, a importância da análise da produção visual permanece. É por isso que propomos pensar nos desenhos da equipe de Mutis como um conjunto. Além da autoria e a individualidade dos desenhistas, o propósito de fazer desenhos para uma expedição da flora americana, para nós, implica um processamento de observações empíricas -do estudo de vários espécimes- e uma condensação do tempo da vida das plantas, desde a aparição do fruto até o nascimento das flores. Então as obras não

\footnotetext{
${ }^{3}$ A citação original diz: "Après celle de Banks, de Londres, je n’ai jamais vu une bibliothèque botanique aussi grand que celle de Mutis». Carta de Alexander von Humboldt a seu irmão Wilhelm, 21 de setembro de 1801. A tradução é nossa.
} 
poderiam ser simplesmente ilustrações, são construções de conhecimento que misturam observação científica com técnica artística. Nesse caso, a cor e a forma não são valores plásticos, mas características traspostas do espécime na obra.

\section{O trabalho duro ao ar livre}

Para entender o caso dos valores plásticos entendidos como características botânicas, analisemos o modo de trabalhar da oficina de pintores. Ao representar espécimes botânicos, deve-se levar em consideração que as plantas murcham e, portanto, alteram suas características físicas. Mas não todas as partes das plantas mudam com a mesma velocidade, e por isso era importante treinar o olhar dos herbalistas -encarregados de achar os espécimes- para reconhecer plantas com flor e fruto no meio do mato. Quando os herbalistas localizavam as plantas, eles as mostravam aos botânicos; Mutis e Valenzuela foram à biblioteca para determinar se eram novas plantas ou se já foram descritas pela ciência. Se as plantas eram adequadas, os artistas receberiam cortes das plantas localizadas pelos herbalistas, para fazer sua representação. Os pintores corriam contra o tempo, porque o desenho tinha que ser feito antes que a aparência da planta fosse afetada. Vejamos uma nota que Eloy Valenzuela faz em seu diário sobre o processo (18 de março de 1784):

Como o desenhista não tem muita facilidade e as flores geralmente não duram muito tempo, foi necessário em muitos desenhos tomar os perfis e a anatomia da flor deixando o que pertence ao polimento da folhagem que nunca falta por mais tempo de descanso (VALENZUELA; PÉREZ ARBELÁEZ, 1983, p. 381). ${ }^{4}$

O que a nota de Valenzuela significa é que a prioridade foi dada à flor e ao fruto. Essas partes são as mais delicadas devido à sua fragilidade e porque determinam o tipo de planta no sistema Linnaeus. Por esse motivo, era realizada uma operação especial chamada de "anatomia botânica", na qual o botânico dissecava a flor junto com o desenhista, para guiá-lo na correta representação das partes do órgão sexual da planta. Nesse momento o desenhista realizava os primeiros desenhos e o cientista fazia o táxon, ou descrição em latim.

Os pintores trabalharam simultaneamente em vários desenhos, deixando as folhagens por último, porque as folhas eram facilmente encontradas ao longo do ano. As folhas não apresentavam um problema menor quando se tratava de pintá-las adequadamente. Como o trabalho era realizado por

\footnotetext{
${ }^{4}$ A citação original diz: "Como el dibujante no tiene mucha facilidad y las flores suelen no durar mucho tiempo, se ha hecho preciso en muchos dibujos tomar los perfiles y la anatomía de la flor dejando lo perteneciente al pulido de la foliación que nunca falta para tiempo más descansado". A tradução é nossa.
} 
camadas pictóricas, era preciso muito trabalho para obter a sua estrutura completa. Dessa forma, a rugosidade, costelas, vilosidades ou manchas que caracterizam as folhas e as identificam como espécies foram descritas no desenho. Muitos desenhos foram necessários para chegar à representação final, o icone de acordo com o nome do momento.

Com o passar do tempo, o estilo da oficina de pintores foi consolidado. Como os ícones deveriam ser transferidos para gravuras, Mutis os comparou com as impressões de livros botânicos em sua biblioteca. É assim que aparece em um relatório ao arcebispo vice-rei Antônio Caballero y Góngora (junho de 1786):

...formei um novo plano de meu trabalho e dirigi meus pintores, submetendo-me a uma espécie de nova tarefa, cujo mérito Vossa Excelência pôde apreciar como testemunha imediata do progresso que esses artistas estão fazendo. Só me faltava, para a minha satisfação, comparar os meus desenhos com as lâminas que foram publicadas nos últimos tempos... (HERNÁNDEZ DE ALBA, 1983, T. I, p. 300-304)

Para finalizar o processo, foram feitas cópias em preto e branco dos desenhos em cores. Essas cópias serviram para orientar os gravadores encarregados de trabalhar na versão impressa das obras da Expedição Botânica. Infelizmente, o trabalho de edição não foi concluído. Mas esses desenhos em tinta-da-china, que imitam gravuras, permanecem como um testemunho para minimizar possíveis erros no processo editorial.

Os desenhos originais em cores foram mantidos, como testemunho da observação dos cientistas, nas coleções dos jardins botânicos. A partir dessas cores, como padrões, era costume iluminar as gravuras já impressas. Dessa maneira, o valor científico dos livros poderia ser completado, se necessário. Esta é uma prática que remonta ao século XVI e continuou a ser usada até que as cores fossem impressas adequadamente. Nesse caso, a cor não é uma forma de decoração, mas constitui uma informação que enriquece as representações botânicas. Na Inglaterra, o botânico Mark Catesby e a artista escocesa Elizabeth Blackwell (1707-1758) editaram obras individuais que eram comercializadas em versões iluminadas à mão, tomando como referência os originais de suas produções. Blackwell foi a autora de $A$ Curious Herbal (1737), um livro de botânica médica contendo quinhentas placas desenhadas, gravadas e iluminadas (conforme solicitado) pela própria autora. Catesby publicou sua Natural History em três volumes, o primeiro aparecendo em 1731, o segundo e o apêndice em 1743 (MEYERS, 1997, p. 18). Cinco anos após sua morte, em 1754, seu colega George Edwards

\footnotetext{
${ }^{5}$ No original: "formé un nuevo Plan de mi obra y dirigí a mis pintores, sujetándome a una especie de tareas, cuyo mérito ha sabido apreciarlo vuestra Excelencia como testigo inmediato de los progresos que hacen estos artífices. Sólo me faltaba para mi satisfacción comparar mis láminas con las iluminadas que se han publicado en estos últimos tiempos..." A tradução é nossa.
} 
reimprimiu a edição original com suas ilustrações. Em 1771, Benjamin White reeditou a versão londrina de Edwards com textos em inglês e francês, incluindo em um catálogo os nomes linnaeanos das espécies estudadas. O trabalho de Catesby foi tão bem sucedido que as edições "piratas" apareceram em Nuremberg entre 1749 e 1776 (MEYERS, 1997, p. 19). Esses livros foram extremamente populares no século 18 e o próprio Mutis tinha exemplares em sua biblioteca. As anotações de comparação aparecem em seus diários entre seus ícones e os de autores "modernos". Então, Mutis decidiu superá-los com imagens que carregavam a precisão da observação científica.

\section{Conhecer e olhar}

Para a historiografia da arte, a partir da ilustração, as produções artísticas feitas a serviço de outras áreas do conhecimento são "menores"; tem valor artístico, mas não pertencem ao sistema acadêmico das Beaux-arts por terem um propósito fora do campo próprio da arte. Ao mesmo tempo, e no mesmo período, para a historiografia da ciência o uso da imagem é contrário à construção do conhecimento. Segundo Platão, em Politeia, a maior conquista de um filósofo é a descoberta de ideias após a natureza aparente. $\mathrm{O}$ aparente, o que se apresenta aos olhos e o terreno da visualidade que a Ilustração - de acordo com Platão- contrapõe as ideias. O conhecimento é construído a partir de conceitos abstratos, comunicados de maneira mais conveniente na escrita. Immanuel Kant na Crítica da razão pura (1781) descreve como o conhecimento pode ser adquirido por meios empíricos; ele explica que todo conhecimento vem da experiência empírica, que se transforma em conceitos abstratos (Begriffe) mais do que em imagens internas. Inclusive a experiência visual (Anschauung) sofre esse processo. $\mathrm{O}$ estudo da imagem cientifica, porém, coloca em discussão essa ideia, ao assinalar outras concepções da imagem no século XVIII.

Barbara Stafford aponta a diferença do uso da imagem entre a Europa católica do sul e a protestante do norte; o protestantismo tem maior desconfiança da imagem que engana, enquanto o catolicismo é partidário do visual que ensina e testemunha ao mesmo tempo que agrada (STAFFORD, 1994). No entanto, o estudo do uso das imagens desde a ciência propõe outras ideias. Lorraine Daston e Peter Galison falam da objetividade como uma atribuição moral do cientista que guia a representação feita pelo artista, até a aparição de meios mecânicos da produção das imagens, quando a objetividade fez-se mecânica (DASTON; GALISON, 2012). Nesta chave, podemos entender a transposição de valores plásticos em dados empíricos a partir da observação científica, como vimos com o uso de cores nas flores e textura nas folhas.

Para dar resposta ao problema das imagens na encruzilhada entre arte e ciência, outras aproximações propõem o visual fora do conceito da representação ilustrativa como elementos 
multicamada no processo epistêmico, fenômenos a serem estudados interdisciplinarmente (BREDEKAMP et al, 2015) ou como Imagens epistêmicas, ou seja, que contêm mais do que o puramente visível, outra maneira de compreender ou conhecer (KLINKE, 2014). Assim, o estudo do desenvolvimento de técnicas pictóricas em conjunto com o desenvolvimento da observação científica ganha valor. Porque não se trata somente de uma questão de habilidade, mas da capacidade de transformação de valores plásticos em dados.

De volta aos desenhistas botânicos, se definirmos as suas produções como imagens epistêmicas é possível dar resposta a uma pergunta sobre a sua formação: Sem uma academia da Coroa e nenhum treinamento para fazer seu labor, como fizeram esses desenhistas para criar uma obra tão complexa para a ciência quanto rica em valores plásticos? Vamos tentar apresentar uma resposta. Se olharmos o conjunto da obra, é tão difícil compreender sua técnica, como reconhecer no meio do mato uma planta o é para uma pessoa destreinada. Então temos que estudar os desenhos da expedição como fontes, fazendo relações entre os desenhos e o momento em que foram criados com os problemas de cada momento.

Por exemplo, falemos sobre a formação técnica da Oficina de pintura. Os desenhos botânicos não são obras do campo artístico, mas da encruzilhada entre a arte e a ciência e, por isso, foi preciso o desenvolvimento de uma técnica particular. No entrecruzamento entre os diários científicos e os desenhos, ou seja, entre fontes escritas e visuais, evidencia-se a luta diária para conseguir transpor na linguagem artística a observação botânica. Em consequência, foi preciso fazer de novo desenhos já feitos, segundo a precisão do estilo que se ia conseguindo com o passar do tempo. Mutis criou o primeiro estilo com Pablo Antonio García del Campo, em preto e branco. Mas em janeiro de 1784 diz em seu diário: "Propus ao meu artista [García del Campo] se seria possível iluminar aqueles [lençóis] já trabalhados com a tinta-da-China. Nos propusemos a fazer o teste com uma folha antiga do iniciante...” (HERNÁNDEZ DE ALBA, 1983: T. II, p. 117, 120). Ou seja, o diretor pretendia mudar as imagens em preto e branco, para o que ia tentar com um desenho feito pelo seu novo desenhista, Francisco Javier Matis (1763-1851). O sucesso do experimento com cores foi chamado pelo diretor de "invenção da cor" em 1784, e dois anos depois já tinha um desenvolvimento maior da técnica com a chegada do novo desenhista Salvador Rizo Blanco (1762-1816); então Mutis fala da existência de dois "estilos sublimes” de pintura: “...um pertence a Dom Salvador Rizo; e o outro é da minha invenção e da execução de Dom Francisco Javier Matis...”’. (HERNÁNDEZ DE ALBA, 1983,

\footnotetext{
${ }^{6}$ No original "Propuse a mi dibujante [García del Campo] si sería factible iluminar las [láminas] ya trabajadas con la tinta de china. Nos propusimos hacer la prueba con una lámina antigua del principiante...”.

7 “...el uno pertenece a Don Salvador Rizo; y el otro es de mi invención y de la ejecución de Don Francisco Javier Matis...".
} 
T. I, p. 300-304). Nesta última anotação é clara a ideia de experimentação pictórica e a de colaboração entre o cientista e o artista.

Além das questões técnicas, ou seja, de desenvolvimento das receitas da cor e da sua aplicação, de um modo geral, o problema está ligado a três variáveis: a sua função, o seu propósito, mas também o seu desenvolvimento no tempo. Assim a questão da formação dos desenhistas é claramente um processo no qual o progresso da observação corresponde a uma necessidade técnica que foi resolvida no momento em que surgiu. Então, contrariamente à visão da historiografia artística, os artistas não tinham que conhecer a técnica antes do começo da expedição. Eles criaram a técnica através da aplicação de soluções pictóricas a casos concretos de representação. Vamos analisar cada uma das variáveis propostas.

\section{Função, propósito e desenvolvimento no tempo}

A primeira variável é a função que tem relação direita com um conjunto de conceitos aceitos amplamente na época, ou seja, um paradigma cientifico: os desenhos faziam parte de um sistema de classificação sexual chamado de Botânica sistemática por seu criador, o cientista sueco Carl von Linnaeus (1707-1778). Em consequência, a reprodução das plantas e seus órgãos era muito importante. Falemos de sexo. O quadro de classificação do Linneaeus é baseado no numero de órgãos masculinos numa flor mas, como não gostava de usar imagens, ele fez uso da descrição escrita em latim ou taxon. Chamou a sua descrição o fio de Ariadne, para sair do labirinto da natureza de acordo com a Philosophia Botanica (1751). Ao contrário, sinalizava os erros frequentes no uso das imagens e o custo da sua edição. Mas o desenho permite reconhecer a planta viva em comparação com as plantas secas no herbário, assim como compreender a proposta do Linneaeus de maneira mais simples. É por isso que teve, para seu arrependimento, muito sucesso com a representação visual da sua botânica sistemática feita pelo gravador holandês Georg Dionysius Ehret (1708-1770), Linnaei methodus plantarum sexuales (1736).

Segundo, o propósito. Essa variável está relacionada ao impacto social ou à aplicação prática do conhecimento botânico. A tarefa mais transcendental da botânica do século XVIII foi o reconhecimento das espécies únicas nos territórios ultramarinos europeus, o reconhecimento daquelas desconhecidas pela ciência e, principalmente, o descobrimento das espécies úteis pela economia como os colorantes (açafrão do mato, pau Brasil, etc.), taninos para fazer tintas de escrever e drogas do sertão. $\mathrm{O}$ avanço econômico da coroa espanhola foi colocado na exploração da riqueza natural de seus territórios, bem como na substituição do comércio por potências rivais. Por esse motivo, Mutis 
dedicou seu maior esforço ao estudo da quina, uma espécie de febrífugo sobre a qual a Holanda detinha o monopólio.

Terceiro, o desenvolvimento no tempo, que tem a ver tanto com o desenvolvimento da técnica de representação, quanto com a técnica de observação científica. Quando vemos os primeiros trabalhos da oficina de pintores e comparamos com os trabalhos de sua época de maior esplendor, temos somente uma parte do panorama que pode nos falar sobre o nível adquirido pelos desenhistas. É evidente que os primeiros desenhos são muito simples quanto os últimos, com as suas cores e maravilhosos detalhes. Mas ao comparar e fazer o cruzamento dos diários científicos com os desenhos aparece a necessidade de Mutis de repetir desenhos já feitos, para enfatizar um detalhe. Quando Salvador Rizo consolidou seu "estilo sublime," Mutis deu a ordem para repetir os desenhos feitos pelo primeiro pintor, Garcia del Campo, na maneira de Rizo (HERNÁNDEZ DE ALBA, 1983, T. I. p. 194-195).

A maneira de conclusão, propormos a importância do estudo tanto das fontes visuais quanto escritas no caso das representações na ciência. Como apresentamos, a arte não foi somente uma serva da botânica durante o século XVIII. O uso do desenho e da cor tinha um propósito bem preciso: dar conta de uma natureza americana aos cientistas da Europa, com o maior detalhe possível. O desenho era a concretização da observação científica, não apenas para fins comunicativos, mas como testemunho de um esforço compartilhado entre arte e ciência para descrever um espécime. Porém trata-se de imagens epistêmicas que ajudaram na construção do conhecimento da natureza americana. Como definiu Salvador Rizo o desenho, numa carta de serviço ao vice-rei, no final da sua vida: ... esta arte preciosa tão necessária para as ciências de demonstração e artes úteis... ${ }^{8}$ (MANTILLA, 1996, p. 520). O orgulho de um trabalho tão impressionante, provavelmente, explica que haja um conjunto dos desenhos da expedição assinados com a inscrição latina Americanus Pinxit, o que podemos traduzir como "foi pintado por um americano", como a testemunha de uma observação cientifica feita arte.

8 “...este arte precioso tan necesario a las ciencias demostrativas y a las artes útiles...". 


\section{Bibliografía}

AMAYA, José Antonio. Mutis, apóstol de Linneo: historia de la botánica en el virreinato de la Nueva Granada, 1760-1783. Dois volumes. Bogotá: Instituto Colombiano de Antropologia e Historia, 2005.

AMAYA, José Antonio; GONZÁLEZ, Beatriz. Pintores, aprendices y alumnos de la Expedición Botánica. Revista Credencial Historia, Bogotá, núm. 74, febrero 1996, (número especial monográfico).

BREDEKAMP, Horst; DÜNKEL, Vera; SCHNEIDER, Birgit. The technical image: a history of styles in scientific imagery. Chicago: The University of Chicago Press, 2015.

GONZÁLEZ BUENO, Antonio. La Naturaleza en imágenes. Los pintores de la Flora del Nuevo Reyno de Granada (1783-1816). In: OZONAS, B. Ribas (edit.). José Celestino Mutis en el bicentenario de su fallecimiento (1808-2008). Madrid: Monografías de la Real Academia de Farmacia, 26, 2009.

HAMY, Ernest-Théodore (ed.). Lettres américaines d'Alexandre de Humboldt (1798-1807). Paris: E. Guilmoto, 1905.

HERNÁNDEZ DE ALBA, Guillermo, (comp.). Archivo epistolar del sabio naturalista don José Celestino Mutis. 2 Tomos (1 y 2, segunda edición). Bogotá: Instituto Colombiano de Cultura Hispánica / Ediciones del segundo centenario de la Real Expedición Botánica, 1983.

KLINKE, Harald (ed.). Art Theory as Visual Epistemology. Newcastle upon Tyne. Cambridge Scholars Publishing, 2014.

MANTILLA, Luis Carlos O. F. M. Recordación del pintor Salvador Rizo 180 años después de su sacrificio. Revista Academia colombiana de la ciencia, Bogotá, Vol. XX, Núm. 78, noviembre, p. 519-525, 1996.

MEYERS, Amy R. W., 1997. “The perfecting of natural history”. Mark Catesby's Drawings of American Flora and Fauna in the Royal Library, Windsor Castle. In: Mark Catesby's Natural History of America, Catálogo de la exposición, Londres, Merrel Holberton/ The Houston Museum of Art, 1997.

DASTON, Lorraine; GALISON, Peter. Objectivité. Bruselas: Les presses du réel, 2012.

STAFFORD, Barbara. Artful Science: Enlightenment and the Eclipse of the Visual Education. Cambridge M. A., M.I.T. Press, 1994.

VALENZUELA, Eloy; PÉREZ ARBELÁEZ, Enrique (edit.). Primer diario de la Real Expedición Botánica del Nuevo Reino de Granada. Bogotá, Instituto Colombiano de Cultura Hispánica, 1983. 